\title{
LA IMPORTANCIA DE NIETZSCHE \\ PARA LAS VANGUARDIAS DE LA ARQUITECTURA
}

Nietzsche's Signifiance for Avant-Garde Architecture

\author{
Arturo Ruiz Salvatierra \\ Universidad de Málaga
}

\begin{abstract}
RESUMEN: Las vanguardias artísticas tomaron el pensamiento nietzscheano más sólido, aquel que representaba Zaratustra, y trataron de buscar las nuevas reglas del arte. Se trataba de vencer todo lo que los críticos del arte y los historiadores habían venido inculcando hasta ese momento. Para ello, el artista debía vencer la saturación de formas a la que se venía asistiendo a finales de siglo. Nada de eclecticismo; el nuevo arte debía arrancar desde cero.

Palabras clave: arte - arquitectura - vanguardias
\end{abstract}

AвSTRACT: Avant-garde artists took the more solid thinking of Nietzsche, which is represented by Zaratustra, and tried to look for new rules of Art. It was a way to overcome what critics and experts in History had wanted to make belief until that moment. For this, the artist had to beat the saturation of forms common in Art in the Nineteenth Century. No Eclecticism; new Art must start from scratch.

Keywords: Art - Architecture - Avant-Garde

El fenómeno de las vanguardias en las artes fue una manifestación muy plural surgida a principios de siglo xx contra el orden artístico establecido. Una serie de acontecimientos artísticos y corrientes de toda índole tuvieron lugar por aquellas fechas. Sin embargo, ese movimiento tan complejo y con tanta diversidad de manifestaciones tenía un sentir común que era fruto de un pensamiento de ruptura que se dio por aquel entonces. Todas esas corrientes tenían una necesidad de desvincularse de lo anterior, buscar la simplificación de las artes y crear reglas para un nuevo lenguaje. Esa necesidad humana de simplificar las cosas surge de una realidad marcada por el fin del Romanticismo y una extensa amalgama de pensamientos convirtiéndose en el corazón de las nuevas artes que surgirían a partir de finales del siglo xix. El individuo durante dos mil años había sido inducido sobre lo que tenía que sentir y no pensaba de manera propia. Así actuó el clasicismo platónico de principios del primer milenio, el cristianismo medieval, la razón ilustrada o el genio romántico. Todos ellos impidieron forjarse una manera propia de sentir, un sentir más hedonista que permitiera al individuo la libre experimentación de las cosas y el arte. Pero si existió un pensador que fue capaz de recoger el testigo del pensamiento vitalista de finales de siglo y de combatir todas esas formas de pensar adoctrinadas decimonónicas; un filósofo que tuvo el 
coraje de enfrentarse al genio romántico y marcar lo que sería la nueva forma de pensar y, con ello las nuevas reglas del arte, ése fue Friedrich Nietzsche.

La importancia del pensamiento nietzscheano para el establecimiento de las vanguardias y la nueva forma de generar las artes es determinante. Los rasgos más importantes de las vanguardias están plenamente relacionados con su pensamiento. La celebración de la vida, la búsqueda de la sencillez, la necesidad de un nuevo lenguaje. Esas nuevas formas artísticas se desarrollaron en todas las disciplinas, sobre todo en las plásticas. Fue muy importante la nueva pintura cubista, la escultura futurista, pero sobre todo la arquitectura, por su condición de disciplina capaz de abarcar a muchas otras, por lo que se desarrolló de un modo verdaderamente determinante en las vanguardias. La influencia de Nietzsche en la arquitectura se deja ver a medida que su pensamiento va madurando. Si en su etapa inicial, en la que reivindicaba una existencia musical del hombre (ligándola con toda la condición efímera del ser), a medida que su pensamiento avanzaba se iba volviendo más sólido. En esta etapa final, Nietzsche solicita del individuo una forma de actuar más reflexiva, meditada y sólida, sin tantos devaneos. Si en su fase inicial de El nacimiento de la tragedia su posición era más combativa que la anterior, su etapa intermedia (en la que escribió su obra magistral Así habló Zaratustra) hizo mella en las vanguardias arquitectónicas por su capacidad de simbolizar un nuevo enfoque del mundo. Aunque en el momento de máximo esplendor de las vanguardias surgió una multitud de corrientes, debemos decir que el origen de esta forma de pensar tiene dos lugares claves: la Viena de finales de siglo y la Alemania de principios de siglo. En ambos lugares el pensamiento de Nietzsche generó el caldo de cultivo necesario para cambiar la manera de hacer arte.

Habría que dividir en tres grandes etapas fundamentales para el desarrollo del pensamiento nietzscheano que tienen su reflejo en la evolución de las vanguardias. La primera, inspirada en el pensamiento primitivo del filósofo. Una segunda, que es la de máximo esplendor por la multiplicidad de ideas y corrientes, y una última, mucho más reflexiva y ordenada para la arquitectura. Sin embargo, todo esto comienza con una etapa previa que tiene su núcleo de acción en una de las capitales más influyentes del arte contemporáneo.

\section{VIENA DE FINALES DE SIGLO COMO ANTECEDENTE DE LAS VANGUARDIAS}

El pensamiento vitalista se introdujo en la ciudad de Viena a través de la figura de Sigmund Freud. Una sociedad con referentes culturales tan importantes pronto incorporaría el pensamiento rupturista nietzscheano a través de su influencia en la filosofía de Wittgenstein, que rompía con la lógica de su primer pensamiento para dejarse incorporar libremente con nuevas corrientes menos teorizantes y más libres de interpretación. En arte todas las disciplinas empezaron a cambiar: una prueba de ello es, el texto de la Carta a Lord Chandos ${ }^{1}$. En éste el autor ya no se reconoce como sujeto en un solo ser, sino que apela a la multiplicidad del Ser. Cuanto del pensamiento dionisíaco contiene este texto. La ruptura de la música de Schoenberg con los criterios tonales de hasta entonces guardan una

1. Cf. H. V. Hofmannsthal, Carta a Lord Chandos, trad. de A. Dieterich, Madrid: Alianza, 2008. 
estrecha relación con un criterio hedonista de entender la música. Una ruptura con lo anterior y un comienzo a no ser influenciados por la crítica o por el genio sobre lo que el individuo debía sentirse. En las artes plásticas: pintura, escultura y arquitectura, comienza a simplificarse los criterios. Muy importante para entender esa búsqueda de la sencillez marcada por la voluntad serán las lecturas de Alois Riegl y Wilhelm Worringer. Ambos comienzan a reivindicar la simplificación de las cosas en base a la sencillez, como el pensamiento que hizo reinar Nietzsche cuando decía: «La simplicidad en el vivir, vestir, habitar, comer, como signo a la vez del gusto más elevado: las naturalezas más elevadas necesitan de lo mejor, ide ahí su sencillez! »².

La influencia de Nietzsche en Riegl le llevó a investigar sobre su pensamiento y le condujo a tratar de buscar el origen de las artes. Riegl pronto detectó que muchas de las artes más abstractas, como el arte industrial tardorromano o el románico, lejos de ser artes menores, contenían un esfuerzo de simplificación y acercamiento al pueblo. Era, por tanto, un arte más de la gente y menos de la crítica y, desde su punto de vista, más elevada. Las artes tardorromanas contenían en su plástica todo el esplendor, la luz y la simplificación necesaria para hombres sencillos. A esa misma conclusión llegaba Worringer que, en su ensayo Naturaleza y abstracción ${ }^{3}$, anteponía el artificio de la plástica generada por el hombre a las leyes complejas de la naturaleza. Esa abstracción, esa sencillez, se imponía a los objetos del arte envolviéndolos como si se tratara de una máscara. De nuevo los conceptos de la apariencia de las cosas, y de que sólo el límite era importante, se incorporaban a las piezas artísticas como una verdadera máscara. De la misma forma en que el vitalismo nietzscheano había dinamitado el yo del sujeto, la máscara se había encargado de otorgarle al objeto artístico la sencillez necesaria. Como Nietzsche lo predijo:

Aquí está la cuna del drama, pues éste comienza con que alguien se enmascara y quiere provocar un engaño en el otro, no más bien en que el ser humano cree que está fuera de sí y se cree así mismo transformado y hechizado [...] En el estar fuera de sí [...] el suelo pierde seguridad, se tambalea la creencia en la insolubilidad y fijeza del individuo ${ }^{4}$.

De esa manera la influencia del pensador en el pintor más importante de la época no se hizo esperar. Las pinturas de Klimt estaban plagadas de recursos lingüísticos de vanguardia: Bordes realzados, planitud, geometrías seductoras, máscaras de seducción en las que se identificaban las figuras femeninas. Se trataba de componer un objeto inabarcable y seductor.

Pero la verdadera revolución plástica de la vanguardia la iba a sufrir la arquitectura, y su comienzo tenía el centro de acción en Viena. La máscara y la sencillez pronto se verían incorporadas a la arquitectura a través del verdadero primer arquitecto moderno: Otto Wagner. El arquitecto había leído el texto de Nietzsche sobre la inutilidad de la historia para la vida. No olvidemos que para el pensador: «La historia, concebida como ciencia pura y convertida en sobera-

2. FP III 515: 25 [352].

3. W. Worringer, Naturaleza y abstracción, trad. de M. Frenk, México: FCE, 1997.

4. OC I 443. 
na sería para la humanidad una especie de cierre y balance para la vida». Tras esas lecturas Wagner escribe su ensayo fundamental La arquitectura de nuestro tiempo ${ }^{5}$. Trata de romper así con el lenguaje anterior situándose en el territorio propio de la máscara. Y es así, en la medida en que el arquitecto deja ya de buscar la verdad en la arquitectura. Comienza a ser la apariencia más nietzscheana del objeto la que logrará la tensión vital. Las piedras no necesitarán ser sillares, sino falsas piedras capaces de seducir a quien las mira. Esa seducción la realizará a través criterios de composición propios del vestir, en lugar de ser criterios de construcción. Para ello sus fachadas se componen simulando pender un tejido de la parte superior. Se trata de envolver el interior, de colocarle el velo de la seducción que enmascara el objeto de la arquitectura.

La abstracción conquistada acabó en una búsqueda de la sencillez y la austeridad de la arquitectura. Fue uno de los pupilos de Wagner, Adolf Loos, quien llevó ese criterio a sus máximas consecuencias. Loos escribiría uno de los ensayos más importantes para la arquitectura Ornamento y delito. La simplificación había pasado así a ser una necesidad imperante y quien no la llevase a cabo tendría que ser considerado un delincuente por su falta de moralidad.

\section{EL EXPRESIONISMO EN LA PRIMERA ETAPA}

Los primeros pasos de expresión de esas arquitecturas abstractas fueron dados por los movimientos de vanguardia de principios de siglo. La corriente expresionista tenía todavía una fuerte componente psicológica y estaba muy condicionada por un pensamiento vital muy energético. El Expresionismo se dio con mucha fuerza en Alemania y los arquitectos más importantes de ese movimiento fueron claramente influenciados por los postulados nietzscheanos. Dos de los arquitectos más importantes de esta corriente fueron Erich Mendelsohn y Bruno Taut.

La figura de Mendelsohn y la influencia constatada6 que Nietzsche despertó en éste fue determinante en esa nueva manera de interpretar su arquitectura en clave dinámica, ello lo define con claridad cuando sobre la arquitectura contemporánea

5. O. Wagner, La arquitectura de nuestro tiempo, trad. J. M. Rovira, Madrid: El Croquis, 1993, pp. 13-14.

6. Mendelsohn cita a Nietzsche en dos de sus cartas que escribió a su novia durante las vacaciones de verano 1911, una vez obtuvo su graduación en arquitectura. En una de ellas se refiere a la introducción reinterpretada del prefacio de El nacimiento de la tragedia: «... Como un libro para iniciados, como una música para aquellos que han sido bautizados en la música, $[. . .$.$] como signo de reconocimiento para parientes de sangre In artibus (en cuestiones$ artísticas)», en la carta n. ${ }^{\circ}$ 28, escrita en Allestein el 22 de julio de 1911. Cf. E. Mendelsohn, "Letters of Erich Mendelsohn", en Archives of histories of art. The Getty Research Institute for the history of art and humanities; o el texto: «Nada nos lleva a avanzar, o madurar más rápido, que estudiar aquellos grandes pensamientos que nosotros comprendimos porque pertenecimos a su estirpe... iQué feliz sería yo si nosotros dos hubiéramos aligerado juntos el vigor del genio combativo! Hay todavía mucho más de él que debes conocer. Debes tener el conocimiento de su Zaratustra", contenido en la carta n. ${ }^{\circ} 29$, escrita en Allestein el 25 de julio de 1911. Ambas son cartas de Mendelsohn a su novia durante las vacaciones de verano 1911, después de obtener su graduación en arquitectura. 
dice: «Lo que hoy en día aparece viscoso e informe, será forjado para convertirse en historia y resultará fantásticamente dinámico y convincente» ${ }^{7}$. El Expresionismo constituye el primer paso contemporáneo en el que se materializan las posiciones de la arquitectura informe. La manera de entender los edificios para el arquitecto comienza a ser, en cierto, sentido más animal. Es en ese contexto en el que Mendelsohn describió la animalidad del edificio de Berhens:

Él revistió sobre la expresiva tensión de la (turbina) entrada, con la rigidez del tímpano de un templo de múltiples roturas, disminuyendo la amplitud de la esquina del tubo hormigón con una horizontal rusificación, y destruyendo su sentido estructural por yuxtaposición de sus irrelevantes formas. Él mete un bloque dentro del otro, una edificación dentro de la otra, como si se tratara de una forma de un organismo que crece, sin una línea de ruptura. En la nueva era como un comando de masas es el sentido del poder de la arquitectura ${ }^{8}$.

Es muy importante esta apreciación de Mendelsohn sobre Behrens, porque él intuye que el segundo se sitúa en la búsqueda de un estilo. Pero esta vez, se trata de un estilo en clave vital. Por eso recurre a interpretar la arquitectura como si fuera un organismo vivo que crece y que contiene piezas imbricadas entre sí.

La expresividad de la edificación tuvo lugar gracias a esa interpretación en clave psicológica de la arquitectura que se estaba llevando a cabo. La expresión tensional del artista en su obra acaba desembocando en la interpretación del gesto en términos freudianos como del desplazamiento del mundo interior condensado9. Esto ayuda a reconocer cómo los artistas expresionistas intentaban plasmar en sus obras ese gesto provocado por los instintos más animales condensados en el hombre. Por eso, según Mendelsohn: «Nuestra tarea consiste en encontrar la expresión arquitectónica para estas fuerzas en movimiento y lograr a través del diseño arquitectónico un equilibrio entre esos esfuerzos, con el fin de controlar la presión interior, el impulso de las fuerzas vitales que provocan estos movimientos» ${ }^{10}$. La incorporación del gesto a las formas del edificio era el resultado de la actitud de embriaguez del artista y de su búsqueda particular del fuera de sí. Así lo plasmaba en sus bocetos previos

7. E. Mendelsohn, «El problema de una nueva arquitectura», en Textos de la modernidad, trad. de S. Marchan, Madrid: Nerea, 1999, p. 172.

8. E. Mendelsohn, Problem einer neuen Baukunst, Berlin, Arbeitsart für Kunst, 1919 citado en (nota 65) Cf. F. Neumeyer, «Nietzsche and modern architecture», en A. Kostka e I. Wohlfahrt (eds.), Nietzsche and «an architecture of our minds», Los Angeles: Getty, 1999, p. 297.

9. Expresión utilizada por Sigmund Freud: «la imagen refleja del mundo interior se superpone en época animista a la imagen que actualmente nos formamos del mundo exterior y la oculta a los ojos del sujeto». Cf. S. Freud, Tótem y tabú, en Obras completas, trad. de L. López-Ballesteros, Madrid: Biblioteca Nueva, 2007, p. 1801. La expresión de la tensión del objeto suponía la liberación de la expresión animal del artista.

10. E. Mendelsohn, «Consenso internacional sobre el concepto de la nueva arquitectura, o dinámica y función", en Viena-Berlín Teoría, arte y arquitectura entre los siglos XIX y XX, trad. de M. García, Barcelona: UPC, 2002, p. 192. «The international consensus on the new architectural concept, or dynamics and function", en America et Amicitia, Amsterdam, 1923; ahora en E. Mendelsohn, Complete works of the architect, London: Princenton, 1992, p. 27. 
y de esa forma acababa materializándolos en edificios tan emblemáticos como los almacenes Schocken ${ }^{11}$.

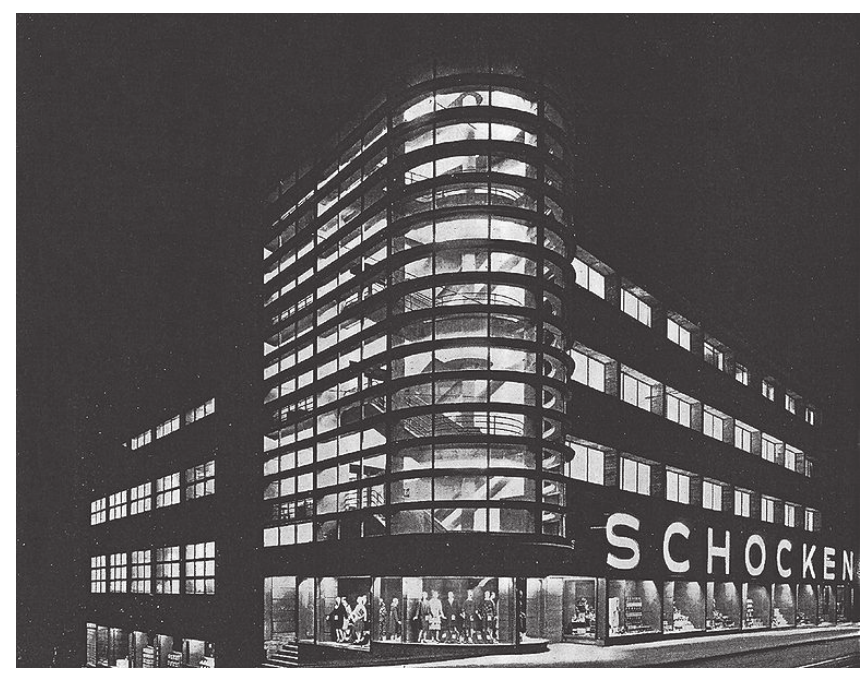

Uno de los arquitectos expresionistas que mejor definió ese sentir fue Bruno Taut. La influencia de Nietzsche sobre éste fue determinante ${ }^{12}$. La interpretación de la arquitectura como manifestación del resultado de una lucha de poder es prueba de ello. Por eso una de sus citas, y con términos muy nietzscheanos, Taut cuenta cómo la arquitectura es el resultado de una agitación política canalizada: «Es una gran corriente única y totalmente homogénea en la que se presentan estas tendencias [...] En ella se halla oculto lo que constituye el anhelo de nuestra época, lo que desea salir y clama por una transfiguración visible: la voluntad de construir nuestro mundo» ${ }^{13}$. Esa simbiosis de energías en arquitectura suponía trasladar la expresión tensional a sus formas plásticas más expresivas y así el edificio emergiera con fuerza. La arquitectura de Taut concebida de esta manera «... se apoya única y exclusivamente en el mundo de sus formas, creadas con libertad, sin imitación del entorno» ${ }^{14}$. Sin duda, tenían mucho que ver esa necesidad de nuevas formas libres en la naturaleza con una huida de la metrópolis que expresaba el sentir general de la sociedad berlinesa de aquella época, a la que se refiere Nietzsche en Así habló Zaratustra cuando dice: «Oh, Zaratustra, aquí está la gran ciudad: aquí tú no tienes nada

11. Almacenes Schocken (1926), situados en el centro de la ciudad de Stuttgart y diseñados por Mendelsohn, en los que la expresividad tensional de sus líneas se lleva hasta la última materialización.

12. En una de las cartas enviadas en $\underline{1094}$, Bruno Taut le cuenta a su hermano la impresión que le ha causado la lectura de Nietzsche (op. cit., p. 107); cf. Bruno Taut and the architecture activism, Cambridge: Cambridge University Press, 1982, p. 301.

13. B. Taut, «La corona de la ciudad», en Escritos expresionistas, trad. de D. Ábalos. Madrid: El croquis, 1997, p. 50.

14. B. Taut, «Sobre el teatro y la música», en ibid., p. 228. 
que buscar y todo que perder $»^{15}$. Esa necesidad de huir de la ciudad, para el arquitecto, llevaba implícita la necesidad de reinventar las nuevas ciudades con otras formas arquitectónicas.

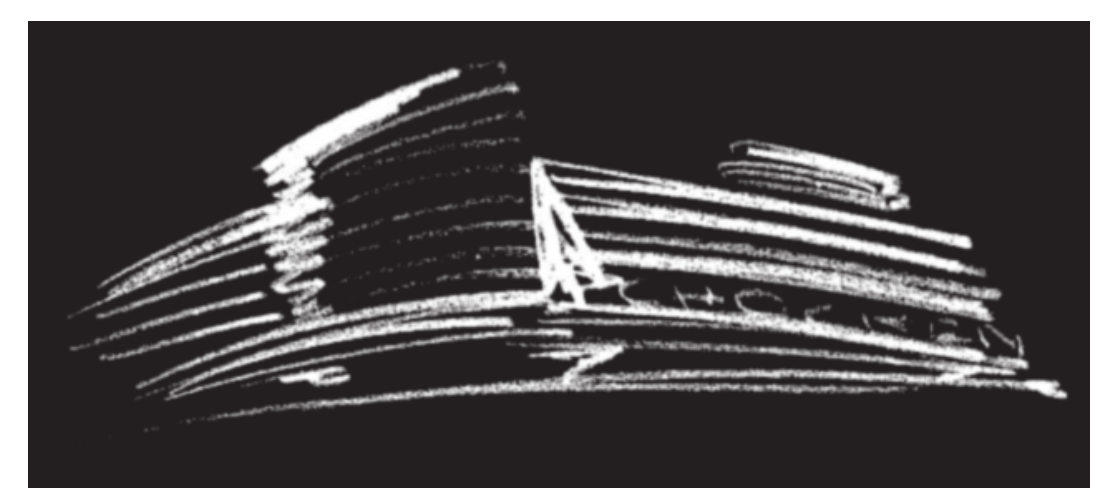

Ese mismo sentir sobre la gran ciudad estaba contenido en el texto de Paul Scheerbart, La arquitectura de cristal ${ }^{16}$, uno de los ensayos más influyentes de principios de siglo. En su texto exacerba las posibilidades de este nuevo material en el territorio a la hora de obtener nuevas formas y matices. Debido a la influencia de éste, los expresionistas experimentan con los nuevos materiales. En ese contexto, Bruno Taut crea uno de los edificios más representativos de esta nueva expresión, el pabellón de cristal ${ }^{17}$. Sin duda, contiene la manifestación de ese sentir del texto de Scheerbart. Con la construcción de éste, nos ofrece la nueva mirada espacial de la arquitectura. Sus muros y cubierta buscan esos destellos expresivos de juegos de luz y la metamorfosis con el territorio. En ese orden de cosas, la arquitectura va un paso más allá en el Expresionismo de Bruno Taut y en sus dibujos utópicos de denominados, La arquitectura alpina. Tal es la influencia nietzscheana en el arquitecto que incluye pasajes de Zaratustra entre sus diseños ${ }^{18}$. Estos bocetos dibujados no llegaron a construirse y, sin embargo, fueron el germen que venía impregnado de un nuevo pensamiento político. Encontramos en ellos una muestra de esa necesidad de nuevos paisajes generados con la arquitectura. Estas posiciones tienen que ver con la necesidad de simbiosis de la arquitectura con el paisaje tratando de crear formas bellas. Las nuevas formas aparecían en el territorio como arquitectura con formas orgánicas de vegetaciones y de cristalizaciones minerales que se

15. Za III «Del pasar de largo», p. 291.

16. Cf. P. Scheerbart, La arquitectura de cristal, Murcia: Colegio Oficial de Aparejadores, 1998.

17. Se trata del edificio más emblemático del Expresionismo alemán. En éste, el autor lleva a cabo una investigación con ese nuevo material y lo hace con la expresión sugerida por Scheerbart y como manifestación de que ese mundo ideal, que sugiere en sus dibujos, es realizable.

18. Bruno Taut incluye diferentes citas del pasaje de F. Nietzsche, Za II «Del nuevo ídolo», pp. 101-104. Para los dibujos que contiene el texto cf. B. Taut, Arquitectura Alpina, Madrid: El croquis, 1997, pp. 83-150. 
mezclaban con el territorio y experimentaban con los nuevos materiales. Estas arquitecturas utópicas fueron tenidas en cuenta en la construcción de las viviendas Lebensraum materializadas en la colonia de herradura Hufeisensiedlung [Ilustración 4] que construyó en Berlín ${ }^{19}$.

Un paso más allá del expresionismo de las formas lo da Hugo Häring con el Organicismo, y así lo manifiesta: «Hemos comprendido que el camino seguido por la vida al formar, estructurar y crear no puede ser más que el mismo seguido por la naturaleza: el camino de una configuración orgánica, no el de la geométrica ${ }^{20}$. En su ensayo realiza un acercamiento a la forma referidos a la voluntad expresiva. Para él esta voluntad es de origen psíquico, y por eso las fuerzas que la expresan son absolutamente subjetivas. Sin embargo, a raíz del surgimiento de la arquitectura expresionista hubo grandes debates en la contemporaneidad. Esa subjetividad del artista, posicionaba de nuevo el núcleo de acción artística en el genio y no era entendida por el usuario de la arquitectura al no identificarse con ella. Por tanto, chocaba frontalmente con la simbiosis artista-espectador que enunciaba Nietzsche en El nacimiento de la tragedia, y que es el objetivo fundamental de la búsqueda del arte contemporáneo. Si la arquitectura para el artista era expresiva, rica en formas y expresión de tensiones; para el arquitecto más transcendente, ésta debía contener en su expresión una sencillez que fuera capaz de captar la atención del espectador. Tanta expresividad gratuita es lo que acaba siendo puesto en tela de juicio en la crítica del genio que hace Nietzsche cuando dice: «La fórmula tiraniza. En el interior de las líneas, una multiplicidad salvaje, una masa avasalladora ante la cual los sentidos se confunden; la brutalidad de los colores, del tema, de los apetitos» ${ }^{21}$. Sin duda, a todos esos juegos fáciles estaba sometido el edificio del Expresionismo.

Estamos ante el gran debate la contemporaneidad, lo pulsional y orgánico contra el orden contenido. Hemos comprobado que esa lucha encarnizada y esos debates de finales de siglo acabaron, primero, con el ornamento y después harían lo mismo con la forma de la arquitectura. Ante la expresividad animal manifestada por el edificio se le oponía la sencillez espacial, estructural y el orden. Esta, sin duda, es la gran discusión del siglo xx y la que se produce entre Häring y Mies en el Plan urbanístico de la Weissenhofsiedlung de Stuttgart ${ }^{22}$.

19. La máxima experimentación Lebensraum se materializó en las Hufeisensiedlung, «colonia de la herradura» que se construyó en el barrio berlinés de Neukölln, en 1933 según el proyecto de Bruno Taut y Martin Wagner.

20. H. Häring, «Wege zur Form»: Die Form 1 (1925). Cf. H. Häring, «Acercamiento a las formas», en Viena-Berlín. Teoría, arte y arquitectura entre los siglos XIX y XX, cit., p. 200. Häring es uno de los arquitectos que incorpora a sus edificios el Organicismo y las formas biomórficas claramente definidas, posiciones que serán muy influyentes al final del Racionalismo.

21. FP IV 309: 10 [37].

22. Nos referimos a la discusión a la que hace alusión Antonio Pizza en su texto cf. A. Pizza, «Berlín, cultura de la trans-formación», en Viena-Berlín Teoría, arte y arquitectura entre los siglos XIX y XX, cit., p. 200, sobre los desacuerdos de Harïng y Mies en relación a la disposición de las edificaciones del Plan urbanístico de la Weissenhofsiedlung de Stuttgart. Tras los bocetos previos, en clave orgánica y con mucho dinamismo en la disposición de la edificación de Häring, Mies había desechado su propuesta para regularizar el trazado de las calles en aras a buscar un orden y más sencillez en su disposición 


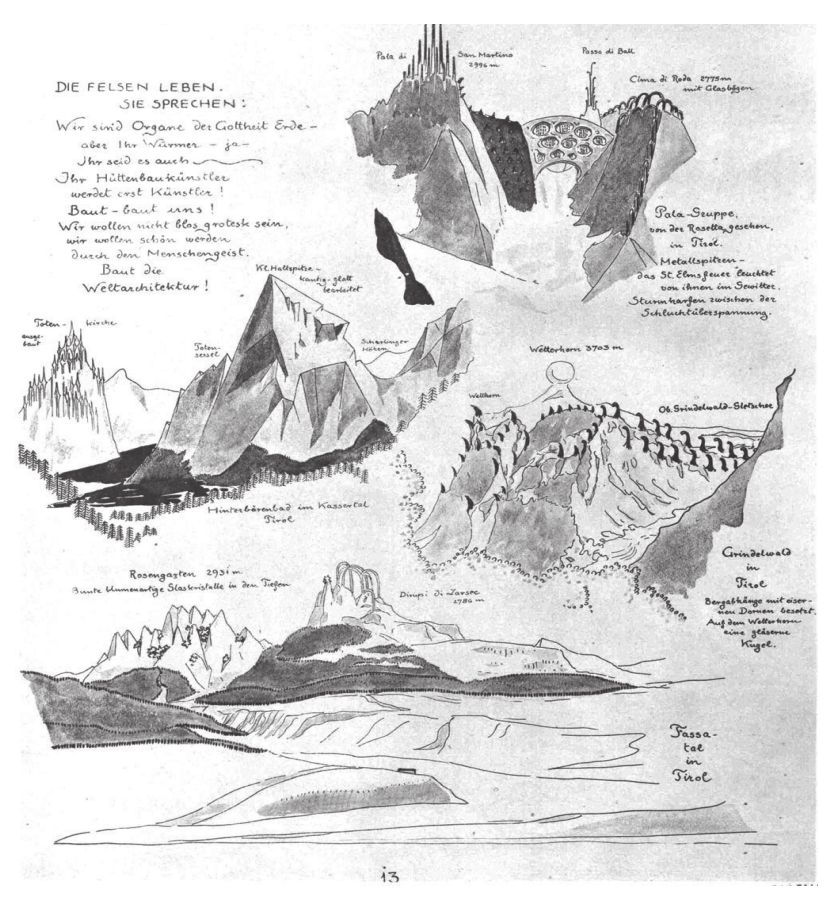

3. DESARROLLO Y ESPLENDOR DE LA NUEVA ARQUITECTURA

El pensamiento dionisíaco no fue el que más glorias deparó a esta disciplina tan pétrea que es la arquitectura. La ruptura por parte de Nietzsche con el pensamiento más energético, o dionisíaco, vino aparejada con un cambio en la valoración de las artes verdaderamente importante. No olvidemos, que la verdadera búsqueda de unas nuevas reglas debía quedar plasmada en una gran construcción capaz de simbolizar la rígida voluntad del hombre. Así lo define Nietzsche cuando se refiere a las artes diciendo:

Extínguese, en fin, la fe fundamental sobre cuya base es factible calcular y prometer, anticipar el futuro y sacrificarlo a su plan, la fe según la cual el hombre sólo tiene valor, sentido, en cuanto es una piedra en una gran construcción: para lo cual tiene que ser ante todo forma, tiene que ser «piedra» [...] iante todo no-actor! ${ }^{23}$.

Nada de actores o poesía ni música que se la llevara el viento, el nuevo arte debía de manifestarse sólidamente como el pensamiento humano. Ese nuevo arte no debía ya de ser el arte del Genio, si no el arte del pueblo.

Las vanguardias artísticas tomaron el pensamiento nietzscheano más sólido, aquel que representaba Zaratustra, y trataron de buscar las nuevas reglas. Había que vencer todo lo que los críticos del arte y los historiadores nos habían venido inculcando hasta ahora. El artista debía superar esa sobresaturación de formas

\section{FW $\$ 356$.}


a la que veníamos asistiendo a finales de siglo. Nada de eclecticismo, debía que arrancarse de cero. Así lo entendió uno de los grandes promotores de las vanguardias, Kasimir Malevich, cuya influencia nietzscheana ha sido ampliamente constatada. El pintor y arquitecto escribió sobre el suprematismo como necesidad de superar el arte anterior. En uno de sus cuadros, Blanco sobre blanco, el autor quiere representar el punto cero del arte. Después de la sobre estimulación decimonónica, había que comenzar a construir nuevas piezas nítidas y serenas. Que inspiraran una nueva manera de abordar las cosas.

Esa idea de serenidad propia de la arquitectura que propiciaba esos misteriosos espacios generados por sencillos edificios fue secundada por De Chirico a raíz de la lectura de Así habló Zaratustra. El hecho es claro cuando declara que:

No, mi querido amigo, esto es una cuestión de diferentes temas juntos. La profundidad, como yo la comprendo, y como Nietzsche la entendió, puede ser encontrada en cualquier parte. Y no tan lejos como la gente la buscó, Mis pinturas son pequeñas... pero cada una de ellas es un enigma, cada una contiene un poema, una atmósfera, un secreto, el cual...tú no puedes y podrás encontrar en otras pinturas $^{24}$.

Sus pinturas contenían arquitecturas serenas y espacios misteriosos que representaban la soledad del hombre. Las vertientes del nuevo pensamiento que se genera a raíz de las lecturas de los textos de Nietzsche por parte de los artistas de vanguardias fueron tan plurales como el arte de vanguardia mismo. Pero todos tienen un denominador común: la búsqueda de unas nuevas reglas y un nuevo lenguaje capaz de romper con lo anterior. Como decía Nietzsche: «Compañeros en la creación busca el creador que escriban nuevos valores en las tablas nuevas» ${ }^{25}$. Pero la única forma de desmitificar el adoctrinamiento anterior era basándose en unas nuevas reglas que reflejaran el arte del pueblo. Tratar de incorporar al pueblo tenía una complejidad. Como supo ver Nietzsche:

La obra de arte artesanal es especialmente incitada a rivalizar con el vecino más culto. La casa alemana debe ser amueblada de manera que se parezca a la francesa [...] él preferiría juguetear, hacer monerías; preferiría aprender maneras y artes, a través de las cuales se embellecen la vida, no aquellas que la transfiguran e ilu$\operatorname{minan}^{26}$.

La necesidad de incorporación de lo cotidiano hacía que la arquitectura cayera en un eclecticismo impropio de un arte tan importante. Para Nietzsche, las artes lejos de pertenecer al espíritu romántico de la moda y de la búsqueda del estilo francés, tenían que pertenecer a ese campo de la búsqueda de su propio estilo. Ese nuevo lenguaje se llamaría a raíz de los avances tecnológicos de primeros de siglo en Rusia Suprematismo y Constructivismo, en Italia Futurismo y Metafísica Surrealista y en Francia o Alemania Dada. Lo que sí fue radicalmente cierto es que el pensamiento de Nietzsche fue utilizado tras el cambio de paradigma político e

24. G. Roos y W. Schmied, Giorgio De Chirico, München 1906-1909, München: Akademie der Bildenden Künste, 1994; citado en Nietzsche and an «architecture of our minds», cit., p. 108.

25. Za «Prólogo» \$9.

26. FP I 572: 35[12] 
industrial para aunar el poder del pueblo, la industria y las artes y fue el referente en la nueva manera de generar los objetos de vanguardia. Llevar el arte al pueblo sólo iba a ser posible a través de la incorporación de la artesanía. Como diría Nietzsche: «Un artesano o un erudito hábil hace bien cuando se siente orgulloso de su arte y mira su vida satisfecho y contento ${ }^{27}$.

El poder del pueblo representado en la artesanía debía aprovechar el potencial de la industria para generar las nuevas reglas del arte. A partir de ahí surgen los nuevas escuelas como las corrientes rusas del Constructivismo, la Werkbund, la Bauhaus, etc. Las nuevas escuelas tenían que ser capaces de educar a la nueva sociedad para incorporar ese nuevo arte más sencillo y enmascarado a todos los objetos de nueva creación. Por eso, la pericia humana debía estar contenida en la propia obra, como diría Nietzsche: «Un artesano o un erudito hábil hace bien cuando se siente orgulloso de su arte y mira su vida satisfecho y contento» ${ }^{28}$. Este arte debía contener grandes dosis de artesanía propia que simbolizaran el espíritu de una sociedad.

El pensamiento zaratustriano de Nietzsche empieza a ser influyente en todos los arquitectos de principios de siglo de Alemania y resto del mundo. En ese sentido, un movimiento alemán tomó por bandera este sentimiento, como lo hizo el arquitecto de principios de siglo, Tessenow. En sus palabras podemos apreciar que para él: "Está claro que el trabajo artesanal exige una formación espiritual y física, como corresponde, en cierto modo, a nuestros valiosos intereses actuales y a nuestras enormes y materiales posibilidades globales ${ }^{29}$. La formación espiritual es la que representaría la contención y seriedad en lo ejecutado, por eso una mejor formación en valores llevaría a una correcta ejecución de esta artesanía. Tessenow, junto a Peter Berhens, abanderan el inicio del surgimiento de ese sentir alemán en la arquitectura e influirán, de manera directa a sus predecesores. Una de las manifestaciones de ese espíritu artesanal se manifiesta en la Bauhaus, en las figuras de Gropius y Mies. Ambos, junto con Van de Velde, influidos por Nietzsche ${ }^{30}$, formaron parte de la dirección de la Escuela de Artes Plásticas y Artesanía, la Bauhaus, y con ello el espíritu de Nietzsche planeó con fuerza sobre las posiciones de la nueva escuela. Son una prueba de cómo el pensamiento zaratustriano y la expresión de una voluntad tenía que ser el reflejo de la arquitectura de ese momento. No en vano el texto de Gropius Apolo en Democracia ${ }^{31}$ trata de describir ese orden necesario para el arte ante tanta sobre estimulación del artista. La Bauhaus fue el resultado de esta experimentación del arte y la artesanía. Uno de los arquitectos más determinantes en esa incorporación de la artesanía a la arquitectura fue Ludwing Hilberseimer. La influencia del pensador en la figura de este arquitecto fue clave para llevar a la práctica la incorporación del nuevo sentir a la arquitectura, para él:

La creatividad es dionisíaca. Crea desde el subconsciente. Hace lo metafísico visible. Lo apolíneo aparece como belleza, la consecuencia de la habilidad. Toma

27. FP III 750: 34[161].

28. FP III 750: 34[161].

29. H. Tessenow, Trabajo artesanal y pequeña ciudad, trad. de J. M. García. Murcia: Colegio Oficial de Aparejadores, 1998, p. 115.

30. Mies y Gropius trabajan en el despacho de Behrens durante los años 1907-1911. Como el propio Gropius, la influencia de Behrens fue notable para su arquitectura.

31. W. Gropius, Apolo en la democracia, Caracas: Monte Ávila, 1968. 
algo en creación y lo hace artística y artesanalmente. El prevalecer del principio apolíneo, belleza, simplemente demuestra la decadencia de todo lo estético ${ }^{32}$.

Las palabras del arquitecto definen con claridad cómo la pericia dionisíaca debía manifestarse en la plástica apolínea. Estamos, ante la clave del nuevo sistema. La sencillez musical de Beethoven tenía que materializarse en arquitectura, porque para él: «Claridad matemática, rigor geométrico, organización funcional, economía extrema y constructividad lo más exacta posible, no son sólo problemas técnicos sino también eminentemente artísticos. Éstos determinan lo que es propiamente de nuestra época» $»^{33}$.

En ese clima de aspiración a una nueva constructividad, a un nuevo lenguaje $\mathrm{y}$, en definitiva, a unas nuevas reglas de la arquitectura en las posiciones teóricas de la Bauhaus tratan de imbricar las nuevas corrientes artísticas, la artesanía y el desarrollo tecnológico. Las tendencias plásticas de las vanguardias ${ }^{34}$ artísticas y las artesanales llegaron a la arquitectura de la Bauhaus a través de la influencia del arquitecto Oud y de su continuador Van Doesburg, integrantes de The Jstil ${ }^{35}$ y del movimiento del neoplasticismo. De esa forma en la escuela se producen estudios de colores, de formas y de utilidad que se incorporan a la arquitectura. Los edificios así generados se entendían como un juego de piezas unidas y una serie de cubos maclados entorno a un espacio central que generaba centrifugando un conjunto arquitectónico. Pintura, escultura y arquitectura se fusionaban en ese nuevo arte. Autores como Gerrit Rietveld fusionaban técnicas como la carpintería artesanal con esas nuevas reglas que iban a marcar la arquitectura del futuro. En ese nuevo entorno en el que se experimenta en la Bauhaus de Weimar se dio el clima artístico propicio para que apareciera la Revista $G^{36}$, como exponente máximo de la vanguardia berlinesa. En ella colaboran arquitectos tan influyentes como Hilberseimer y Mies Van Der Rohe.

En ese mismo contexto, pero con sede en París, aparece el arquitecto más influyente de la contemporaneidad, Le Corbusier. Éste experimentaba con diversas artes y también se dedicaba a la pintura, seguía los pasos de los suprematistas experimentando con formas abstractas en los cuadros y generó un estilo denominado purista. Sin embargo, la importancia de éste para la presente investigación es la influencia del pensamiento más trascendente de Nietzsche, la cual podemos

32. L. Hilberseimer, «Nietzsche and Modern architecture», en Nietzsche and an «architecture of our minds», cit., p. 290, citado en «Typescript 'schoepfung und entwicklung' VIII, en Hiberseimer papers, The Art Institute of Chicago, Folder 10.

33. L. Hilberseimer, "Notas sobre lo nuevo», en Viena-Berlín Teoría, arte y arquitectura entre los siglos XIX y XX, cit., p. 198.

34. Movimientos como los suprematistas, cubistas, puristas, etc., trataban de escribir las nuevas reglas del arte y tenían un espíritu de ruptura con respecto a lo anterior que obligaba a reescribir los nuevos dictados artísticos.

35. JStil es un movimiento artístico que había tomado el nombre de la revista que se edita en 1931 que se titula en holandés «territorio de donde procede» el estilo. Las piezas artísticas generadas con esta influencia artística utiliza formas sencillas y colores puros. En este movimiento, Theo Van Doesburg (1883-1931) es uno de los artistas más influyentes de esta corriente y Jacobus Johannes Pieter Oud (1890-1963) el arquitecto más determinante en la conexión de este arte con la Bauhaus.

36. Revista G (Zeitschrift für elementare Gestaltung) es una revista en la que colabora Mies entre 1923 y 1926 además de personajes de la talla de Hans Arp, El Lissitsky, Tristan Tzara, Walter Benjamin, Georg Gross o Ludwig Hilbereimer. 
verificar en diferentes documentos ${ }^{37}$ [Ilustración 6], además de constatarla en su arte y su actitud ante la vida ${ }^{38}$. Le Corbusier aplica las nociones de la metafísica más vital para la generación de esas nuevas formas en pintura cubista y arquitectura. Para éste, como para Nietzsche, las posiciones trascendentes las proporcionaba la vida: «El arquitecto tiene por misión dar vida a las superficies que envuelven esos volúmenes...» ${ }^{39}$. De ahí podemos intuir que es en sus comienzos donde sus posiciones trascendentes son más marcadas.

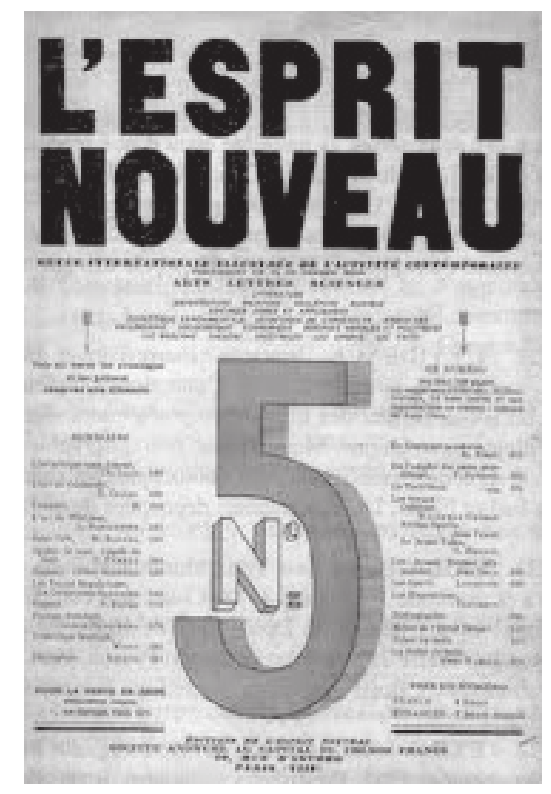

37. Se conoce que el texto de Nietzsche Así habló Zaratustra fue leído por Le Corbusier en su juventud por una inscripción que resulta en un ejemplar de este libro hoy depositada en la fundación Le Corbusier de París. Cf. F. Nietzsche, Ainsi parlait Zarathoustra, trad. de H. Albert, Paris: Mercure, ${ }^{15} 1908$. Dicha inscripción dice: «No he leído este libro desde 1908 — 51 años— mi vida de hombre hoy, hojeando páginas adivino situaciones, hechos, destinos, que son hechos de hombres. Decido anotar las páginas». En 1961 cuando vuelve a leer el texto señala vigorosamente una frase «por amor la mano abierta». Cf. Za «El niño en el espejo». La apertura de la mano la reflejó en su texto Le Corbusier, El poema del Ángulo recto, Madrid: CBA, 2006.

38. Le Corbusier era un esteta en el más amplio sentido de la palabra, tan es así que como pocos otros, el arquitecto decide despojarse de su persona anterior, Charles-Edouard Jeanneret, e inventa un personaje artístico. ¿Acaso no estamos ante una sutil interpretación de la multiplicidad del ser? Cuando dice: «Le Corbusier es un seudónimo. Le Corbusier trabaja exclusivamente en arquitectura. Él sigue ideas desinteresadas. Él no tiene derecho a comprometerse a través de traiciones y acomodaciones. Él es una entidad libre del peso de la carne. Él nunca debe (¿se organizará?) caer. Ch. Edouard Jeanneret es el hombre carnal, quien ha experimentado todas las aventuras —emocionándose o angustiándose - en una vida bastante memorable», se trata de la carta a Josef Cerv, 18 de enero de 1926, citado en Le Corbusier, La vie et le urbanisme après Le Corbusier, Actes du Colloque des 23-26 septembre, Chaux-de-fonds: En Haut, 1987. La referencia al cuerpo y el espíritu en el texto de Zaratustra y la constante búsqueda de la libertad en éste, es una prueba más de la influencia que el texto produjo en el autor.

39. Ibid., p. 25. 
En la exposición que realiza en París, denominada El espíritu nuevo ${ }^{40}$, el arquitecto contenía ya esa actitud afirmativa contagiada del espíritu zaratustriano. Es por aquel entonces cuando Le Corbusier promulga con fuerza la necesidad de un nuevo lenguaje en arte y arquitectura: «una gran época acaba de comenzar» ${ }^{41}$. Esa ruptura con lo anterior se llevaría a cabo hibridando todas las artes. En estas nuevas reglas el sentido geométrico impregnaría sus composiciones edilicias, pues en este principio residía la manifestación de orden y poder. Buena cuenta de ello nos ofrece su discurso sobre las formas puras: «Este campo de líneas y formas que satisfacen nuestros sentidos, verificamos una vez más que la geometría es todopoderosa [...]. Sepamos que estamos en una época que gracias al maquinismo, vivimos en cohabitación efectiva con las formas puras ${ }^{42}$. La disposición de esas formas, que expresaban pureza, había que realizarla en el juego zaratustriano, aplicado a las libres formas del edificio. Su arquitectura consistía en el «juego sabio, correcto y magnífico de los volúmenes reunidos bajo la luz» ${ }^{43}$. El juego como experimentación lo lleva hasta sus últimas consecuencias al organizar los recorridos del edificio en clave teatral ${ }^{44}$. La arquitectura como juego de formas puras fue la clave de la arquitectura contemporánea y, desde entonces, no hemos borrado el rastro que Zaratustra ha dejado en la edificación contemporánea. Ya nunca más los edificios de la modernidad volvieron a reclamar lenguajes arquitectónicos de antaño. En Le Corbusier, el arquitecto más influyente de la modernidad, se dan una a una todas las transformaciones que hemos ido viendo a lo largo de esta investigación: el despojarse de la historia, la abstracción en las formas, el resurgir de unas nuevas reglas y el juego de la arquitectura.

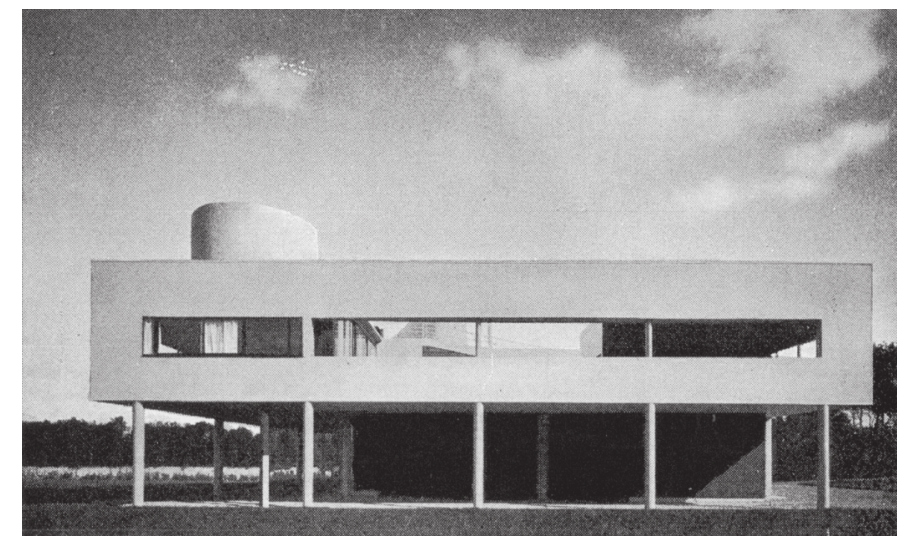

40. A fin de expresar sus ideas sobre la arquitectura y la pintura, Le Corbusier fundó en 1920 con Paul Dermée una revista de divulgación, L’Esprit Nouveau.

41. Le Corbusier, El espíritu nuevo en la arquitectura, trad. de M. Borrás y J. M. ${ }^{a}$ Forcada, Murcia: C Oficial de Aparejadores, 2003, p. 10.

42. Ibid., p. 34.

43. Le Corbusier, Hacia una arquitectura, trad. de J. Martínez, Barcelona: Apóstrofe, 1998, p. 16.

44. Los recorridos fenomenológicos del autor se fundamentan en una rampa central que recorre el edificio ofreciendo un sinfín de imágenes interiores a partir de las cuales el usuario debe hacerse una idea del todo a partir de la aprehensión de sus partes. Esta idea la hereda el arquitecto del estudio a fondo del arte griego. 
Le Corbusier aspira a lo más alto en sus formas, como buen seguidor de las posiciones más trascendentes zaratustrianas: «Hacia la altura quiere edificarse, con pilares y escalones, la vida misma: hacia vastas lejanías quiere mirar, y hacia la bienaventurada belleza, por eso necesita altura! $»^{45}$. Sin embargo, al arquitecto esa búsqueda de altura le hizo olvidarse de la tierra. Su arquitectura se construiría elevándose sobre pilotis ${ }^{46} \mathrm{y}$ se genera en la parte baja del edificio, como él mismo decía: «un bosque de pilares ordenados sobre el cual la ciudad habría hecho intercambio de mercancías» ${ }^{47}$. Es así, como concibe su edificio más importante, La villa Saboya ${ }^{48}$. Un bosque de pilares que sostiene un volumen puro que flota.

\section{LA ABSTRACCIÓN METAFÍSICA DEL OBJETO}

Después de tanta experimentación con el objeto del arte, tras una búsqueda de nuevos sistemas de construcción para el nuevo lenguaje de la arquitectura, tocaba impregnar de un orden a ese objeto. La arquitectura, que hasta entonces había estado buscando sus reglas, tenía que obedecer a unas reglas claras y condicionantes, un orden sereno fuera de tanto juego y experimentación. En ese contexto nace el último objeto arquitectónico de vanguardia que será, a la postre, el primero del minimalismo en la posvanguardia. La abstracción de las piezas artísticas derivó en un grado mucho más condicionante hacia el objeto. El grado de abstracción en el objeto acabó siendo casi un dogma, impregnando la pieza como si ésta obedeciera a dictados superiores. Las reglas del arte comenzaban a perder esa libertad vital para otorgarle una cierta autoridad. Así concluyen las vanguardias con autores como Piet Mondrian o Theo Vandoesburg generando el lenguaje casi alienante que derivaría en el minimalismo más nítido.

El personaje de Nietzsche Zaratustra fue interpretado de forma tremendamente metafísica por autores que vieron en él una mezcla divina y humana. Interpretaciones teológicas, como las de Heidegger y Guarini, propiciaron la última gran influencia vanguardista en arquitectos como Mies Van Der Rohe. Por ello, la arquitectura de Mies comienza a conformarse en la medida en que recapacita sobre la idea de voluntad, ese concepto que a lo largo de la contemporaneidad había suscitado tantas interpretaciones como manifestaciones arquitectónicas. El sentido de la voluntad para Mies comienza a ser algo más profundo, tiene más que ver con el deber y orden sobre las cosas. Por eso desecha posiciones anteriores cuando dice: «Ni sentimentalidad ni una voluntad brutal son características adecuadas. La fuerza de la vida también apartará un día estas ridiculeces, y entonces encontrará su formación a gran velocidad ${ }^{49}$. Ni los sentimientos ro-

45. Za II «De las tarántulas», p. 178.

46. Se trata de una forma de disponer la edificación como un cuerpo completamente suspendido de columnas. Era una forma de mejorar las condiciones higiénico-sanitarias en un clima tan denso y agitado, pero también una forma de elevarse propia del pensamiento que estamos tratando.

47. Le Corbusier, Hacia una arquitectura, trad. de J. Martínez, Barcelona: Apóstrofe, 1998, p. 45.

48. Villa Saboya es realizada en 1929 en los alrededores de París. En ésta, su autor experimenta los nuevos posicionamientos artísticos de manera clara.

49. M. v. d. Rohe, «Sobre la forma en arquitectura», en La palabra sin artificio, trad. de J Sigúan, Madrid: El Croquis, 1995, p. 393. 
mánticos, ni la tensión expresionista podían organizar su arquitectura. Con esto, Mies se estaba apartando de ciertos conceptos, que él tacha de ridiculeces, de los artistas y del sentir de la crítica. Llegó la hora de recapacitar para el artista y de hacer que su obra surgiera con una voluntad contenida fruto de un esfuerzo. En la manifestación de la arquitectura debe darse la suma de esas voluntades y la expresión de la lucha del individuo en coalición con su civilización por ofrecer un orden. Lo que expresa Mies con sus edificios es lo que él mismo escribió: «iArquitectura y voluntad de época! $»^{50}$. Es esa necesidad de trascender sobre las banalidades y temas superfluos de la vida. Estábamos asistiendo a la incorporación en la arquitectura del sentir más trascendente del que hablaba Zaratustra. La superación de sí mismo y la necesidad de elevarse se manifestaba en su modo de operar con la arquitectura, por eso la describe como: «Ascensión progresiva desde el origen hasta el último peldaño de la configuración, donde se manifiesta la forma; con ello se satisface el significado y tiene un sentido» ${ }^{51}$.

El edificio de Mies es un producto del deber, en él no queda nada aleatorio. Para este arquitecto, los criterios que formaban la arquitectura respondían a una metafísica vital, por eso cuando le preguntan por temas como los estilos, techos inclinados o la forma de la arquitectura, Mies se queja de la crítica arquitectónica de su época y dice que estaban ante una lucha en la que «se combate con una energía, como si se tratase del aspecto más crucial de la arquitectura [...]. Sin embargo, esta batalla se desarrolla a otro nivel y sólo es una parte del gran combate por unas nuevas formas de vida ${ }^{52}$. El nivel en el que se libra su batalla tiene más profundidad, es una fuerza que lo impregna todo. La arquitectura de Mies contiene sencillez en sus formas y abstracción, como en la etapa anterior, pero esta vez la sencillez es fruto de una posición ante la vida, de una actitud austera ante lo no necesario y derrochadora ante lo vital. El servicio y la obediencia por la que se rige, que es el sentimiento fuerte y formado, están relacionados con eso a lo que apelaba Nietzsche cuando reivindicaba formación en términos morales. Las posiciones instaladas en el pensamiento de Mies se vuelven más trascendentes, si caben, al recibir la influencia de la teología de Romano Guardini ${ }^{53}$. Prueba de ello la encontramos en las notas que hacen referencia a Las cartas del Lago Como del teólogo, una de ellas habla de la arquitectura, al decir: «Técnica en todos sitios, también en lo espiritual $\aleph^{54}$. Esa espiritualidad y esa fe hacen que Mies contenga en su arquitectura un sentido de servicio y obediencia muy superior al de los arquitectos anteriores. Parece curioso que esa trascendencia zaratustriana, que necesitaba sencillez y clasicismo aplicados a la vida y a la arquitectura, haya tenido su primera materialización en la arquitectura de Mies y su influencia más teológica.

Tras el análisis del desarrollo de la arquitectura a través de las vanguardias podemos decir que la figura de Nietzsche fue determinante para las vanguardias y sobre todo para la arquitectura de aquella etapa. Las corrientes de las vanguardias artísticas inspiradas en Nietzsche fueron aquellas que enmascara-

50. M. v. d. Rohe, «Artículo publicado en la revista Der querschnitt», en ibid., p. 371.

51. M. v. d. Rohe, «Apuntes para conferencias Drafts and Speches», en ibud. p. 493.

52. M. v. d. Rohe, "Conferencia en Dusseldorf», en ibid., p. 400.

53. Teólogo italiano que en 1923 obtuvo una plaza de Filosofía en Berlín. Su filosofía y teología estaban relacionadas con el arte.

54. M. v. d. Rohe, «Apuntes para conferencias», en La palabra sin artificio, cit., p. 410. 
ron el objeto y lo volvieron seductor, dinamitaron las formas con el expresionismo de los espacios de la arquitectura y generaron otra arquitectura a través de un nuevo lenguaje a las órdenes de escuelas de experimentación. El último estadio de las vanguardias, el más metafísico orden que impregnaba al objeto y cada una de las piezas que componía la arquitectura. 